\title{
Increasing Task Behavior in a Language Arts Program by Providing Reinforcement ${ }^{1}$
}

\author{
Donald E. P. Smith, Dale Brethower, and Raymond Cabot \\ Center for Research on Language and Language Behavior, University of Michigan
}

\begin{abstract}
The work of retarded readers using a programmed language arts curriculum was observed under various conditions of reinforcement in a controlled classroom. Task behavior was followed by conditions of no consequence, teacher praise, a work-break consequence, a monetary consequence and feedback on amount of work (relative to previous work). Extinction of task behavior tended to occur under conditions of no consequence and of teacher praise. Conditions of monetary consequence and of feedback on progress resulted in high, sustained rates of work behavior.
\end{abstract}

Maintenance of task behavior is a chronic problem in classrooms and clinics. Common pedagogic terms for classifying the problem are "inattention," "lack of motivation," and "undisciplined behavior."

Common classroom techniques for increasing task behavior include teacher praise, withholding punishment, assigning grades and inducing a commitment by means of a contract. This paper reports the results of several experiments designed to increase task behavior in a controlled environment, i.e., in classrooms wherein instructional materials and teacher behaviors are controlled and wherein the dependent variable is rate of work, i.e., correct task responses per hour.

The problem of maintaining task behavior arose during the validation of a programmed language arts curriculum. ${ }^{2}$ The program, designed for use in first grade classrooms and in clinics, consists of 16 books containing some 17,000 tasks, scripts (or tapes) for teacher participation, and a programmed manual for training the teacher in his role. The program trains reading, writing, listening, and speaking behaviors with

${ }^{1}$ The research reported herein was performed in part under Contract OEC-3-6061784-0508 with the U. S. Department of Health, Education, and Welfare, Office of Education, under the provisions of P.L. 83-531, Cooperative Research, and the provisions of Title VI, P.L. 85-864, as amended. This research report is one of several which have been submitted to the Office of Education as Studies in language and language behavior, Progress Report V, Scptember 1, 1967.

${ }^{2}$ Smith, D. E. P. (Ed.) Michigan Language Program. Ann Arbor; Ann Arbor Publishers, 1964, 1965, 1966, 1967. 
tasks ranging from matching letters and utterances, initially, to reading paragraphs orally and silently as terminal behaviors. The lcarning tasks were constructed iteratively, within classrooms, until an error rate below $5 \%$ was achieved on each book.

'The teacher's role is that of classioom manager. He arranges the classronm, provides tasks and matcrials, and provides fcedback on performance. Performance feedback is carefully controlled and predictable. Under normal operating conditions, feedback on task relevant performance is provided by the programmed materials which are self-selected and self-paced. Feedback on non-task performance is provided by establishing a limited number of rules-usually one. Non-task performance not covered by the rule is followed by no consequence other than being noticed; performance covered by the rule is always followed by a specific enforcement procedure, i.e., stating the child's name and requesting a restatement of the rule ("John, what is the rule?").

Within these limits, children are free to work or not to work. It should be noted that most of the teaching frames are of the discrimination type and control the attention of most children in a stable, predictable environment. A "frame" in this program is defined as a task requiring a discriminative response or a production. A response, then, is defined as completion of a single task-circling a letter, indicating same or different, spelling a word, writing a dictated sentence, etc. Rate of work is determined by counting the graphic evidence of responses, either the trained response (such as the spelling of a word) or a "token" response (such as circling).

Rate of work in normal classrooms under the above conditions tends to be high (i.e., 200 correct responses per hour). However, teacher reports of extinction curves for isolated cases were confirmed by similar data on a substantial proportion of clinic cases.

In an attempt to resolve the problem of maintaining task behavior, a series of six experiments was carried out. The independent variable in each was none, one or a combination of consequences following task behavior. The first two experiments demonstrate the results of no consequence and of a monetary consequence precisely contingent upon amount of task behavior. The next three experiments report results under conditions approximating each of these extremes. The last study reports the effect of a non-monetary consequence feasible for school use.

\section{Experiment 1: No Consequence}

Procedure. Ss were six children designated "non-verbal, first-grade failures" by their school principal (Table 1). Ages ranged from 70 months to 98 months. Reading skill deficiencies ranged from 1 month to 
6 months (Gates Primary: Word Recognition). Classes met 50 minutes per day, 4 days per week for 10 weeks. Conditions and materials were as described above. No consequence followed work behavior.

Results. The cumulative curves depicting rate of work (Figure 1) characteristically demonstrate extinction of task behavior. Reduced outputs were usually accompanied by emotional behaviors, attacking self and others, "escape" responses, curling in a fetal position, sitting under the desk, etc. Under these conditions, mean rate of work was 39 responses/hour.

Discussion. The condition of no consequence following task behavior results in a low rate of work, rapid extinction of task behavior and a substantial amount of infantile attack and withdrawal behavior.

TABLE 1

Work Output of Retarded Readers under Conditions of No Consequence for Task Relevant Behayior

\begin{tabular}{|c|c|c|c|c|c|c|}
\hline \multirow[b]{2}{*}{ Subject } & \multirow[b]{2}{*}{ Sex } & \multirow{2}{*}{$\begin{array}{c}\text { Age } \\
\text { (months) }\end{array}$} & \multirow{2}{*}{$\begin{array}{r}\text { Grade } \\
\text { place- } \\
\text { ment }\end{array}$} & \multirow{2}{*}{$\begin{array}{l}\text { No. of } \\
\text { scssions }\end{array}$} & \multicolumn{2}{|c|}{ Responses } \\
\hline & & & & & Total & $\bar{x}$ \\
\hline A & $\mathbf{M}$ & 98 & 1.9 & 21 & 1650 & 78 \\
\hline B & M & 70 & 1.9 & 26 & 1100 & 42 \\
\hline $\mathrm{C}$ & $\mathbf{M}$ & 88 & 1.9 & 24 & 800 & 33 \\
\hline $\mathrm{D}$ & $\mathrm{F}$ & 71 & 1.9 & 7 & 500 & 71 \\
\hline $\mathrm{E}$ & M & 70 & 1.9 & 25 & 600 & 24 \\
\hline $\mathrm{F}$ & $\mathbf{F}$ & 66 & 1.9 & 27 & 350 & 13 \\
\hline
\end{tabular}

Experiment 2: Monetary Consequence, Task Contingent

Procedure. Ss were six children taken in order from a waiting list and assigned to a class taught by the teacher used in Experiment 1. Ages ranged from 101 months to 136 months. Reading skill deficiencies ranged from 1.1 years to 2.7 years. Children were described by their teachers as hyperactive (2), anxious (1), passive-aggressive (2), aggressive, actingout (1) (school placement in a classroom for disturbed).

Classes were held for 45 minutes, 4 days per week, with the same physical arrangements and materials as before. Two rules obtained, "No talking during independent work," enforced as above, and "No disturbing others," enforced by exclusion for the remainder of the hour. Immediately following the class, correct responses were totaled, in the presence of the child, and a monetary pay-off occurred. The child was paid at a rate of one cent for ten responses by the office secretary.

Results. Ratc of work began at 100 responses per session and reached a mean of 430 responses per session during the last four meetings 


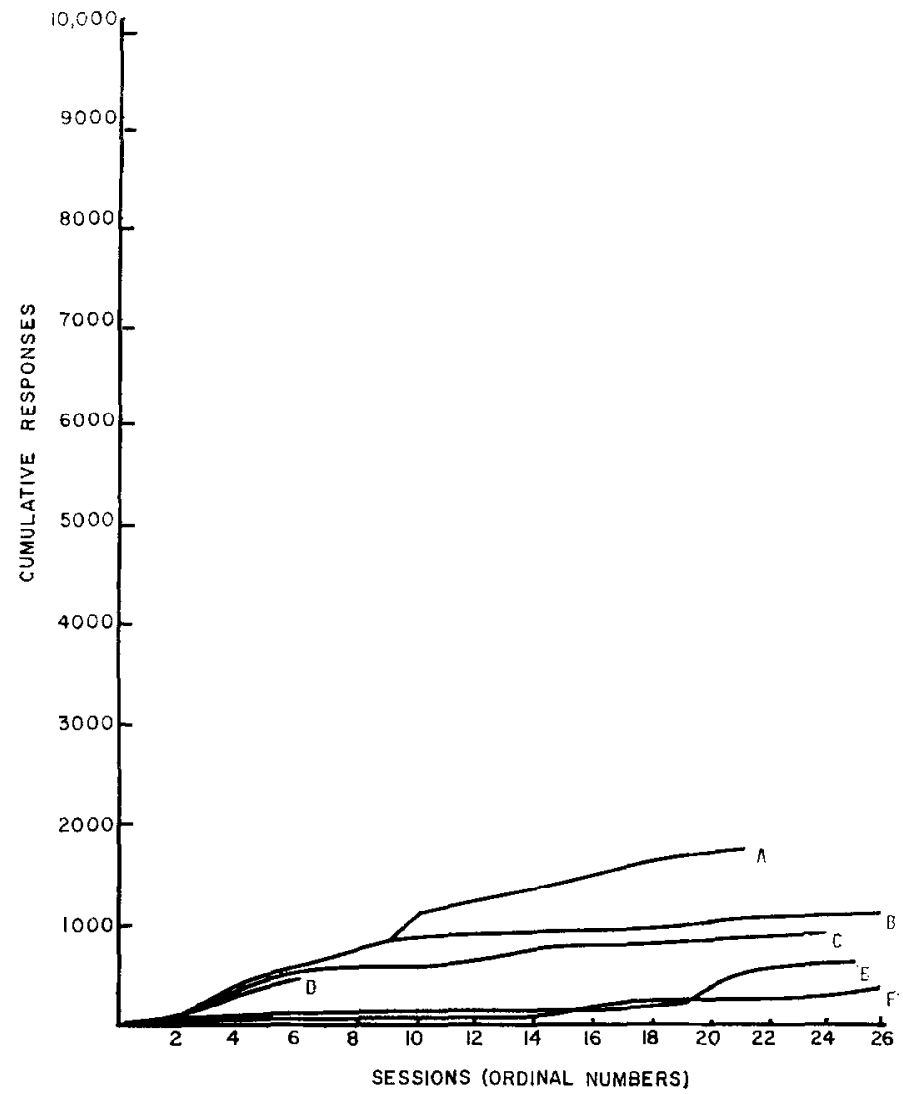

Fra. 1. Work output of retarded readers under conditions of self-selection, selfpacing and no consequence.

TABLE 2

Work Output of Retarded Readers under Conditions of a Monetary Consequence Contingent upon Number of TASKS COMPleted CORRECTLY

\begin{tabular}{|c|c|c|c|c|c|c|}
\hline \multirow[b]{2}{*}{ Subject } & \multirow[b]{2}{*}{ Sex } & \multirow{2}{*}{$\begin{array}{c}\text { Age } \\
\text { (months) }\end{array}$} & \multirow{2}{*}{$\begin{array}{c}\text { Grade } \\
\text { place- } \\
\text { ment }\end{array}$} & \multirow{2}{*}{$\begin{array}{l}\text { No. of } \\
\text { sessions }\end{array}$} & \multicolumn{2}{|c|}{ Responses } \\
\hline & & & & & Total & $\bar{\chi}$ \\
\hline A & $\mathbf{M}$ & 117 & 4.6 & 24 & 7000 & 292 \\
\hline B & $\mathbf{M}$ & 124 & 4.6 & 24 & 6400 & 267 \\
\hline $\mathrm{C}$ & $\mathbf{M}$ & 136 & 5.6 & 20 & 5775 & 289 \\
\hline D & $\mathbf{M}$ & 112 & 4.6 & 23 & 4600 & 200 \\
\hline $\mathbf{E}$ & $\mathbf{F}$ & 101 & 3.6 & 18 & 3825 & 212 \\
\hline $\mathbf{F}$ & $\mathbf{M}$ & 114 & 3.6 & 16 & 3400 & 213 \\
\hline
\end{tabular}


(Figure 2). All curves are accelerating positively by Session 16. Mean proportion of time spent in task behavior exceeded $90 \%$ on three of the last five sessions.

Gains in reading skill are reported in Figure 2A. Test data indicate no change over the 6 weeks during which rate of work data was recorded. Five of the six $S$ s continued treatment through 14 weeks by which time they had completed the program. Whereas mean deficiency was two grades and remained so after 6 weeks, mean final deficiency is slightly less than .6 grades or an achievement level of grade 4.0 , the upper limit of the program as now constituted. "Expected achievement" is based upon mean chronological age. The mean gain of 1.4 grades may be compared with a median gain of .4 grades achieved by a sample of 50 similar children treated in the year prior to this study.

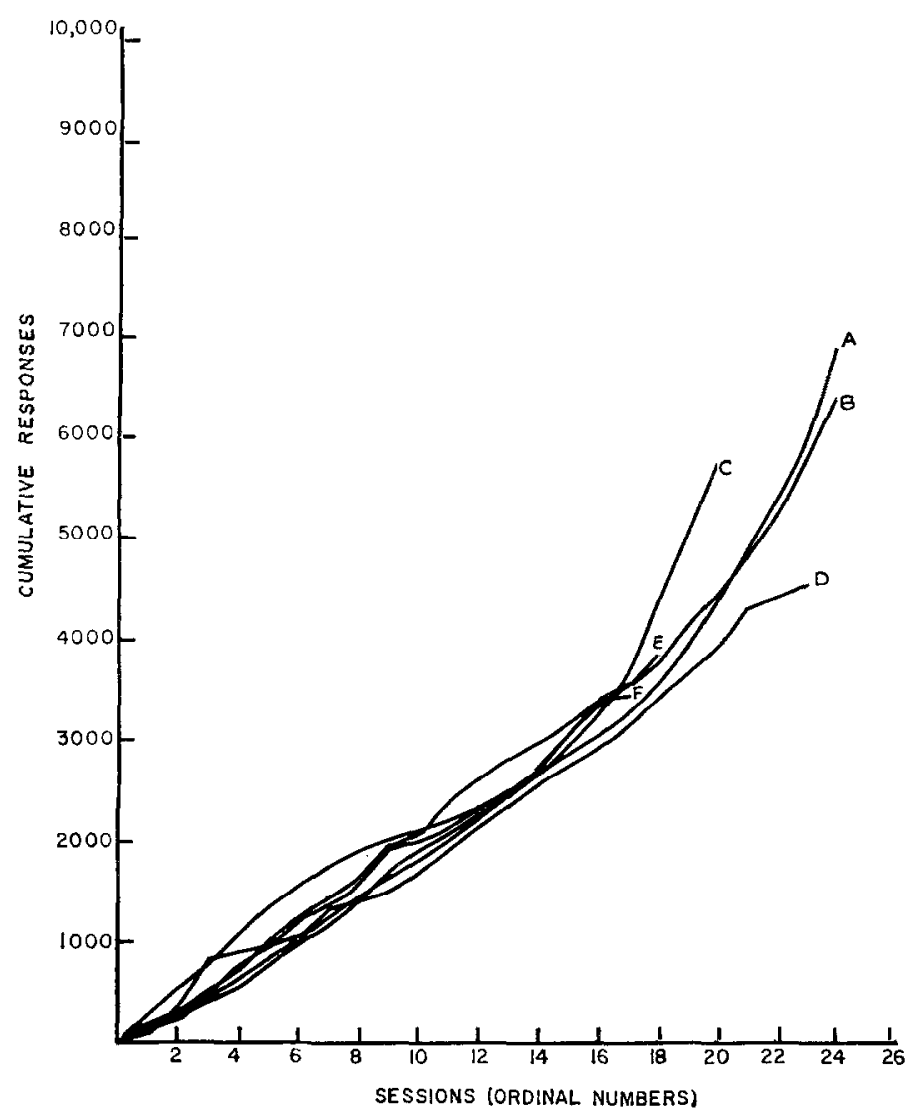

Fia. 2. Work output of retarded readers under conditions of self-selection, selfpacing, and a monetary consequence. 


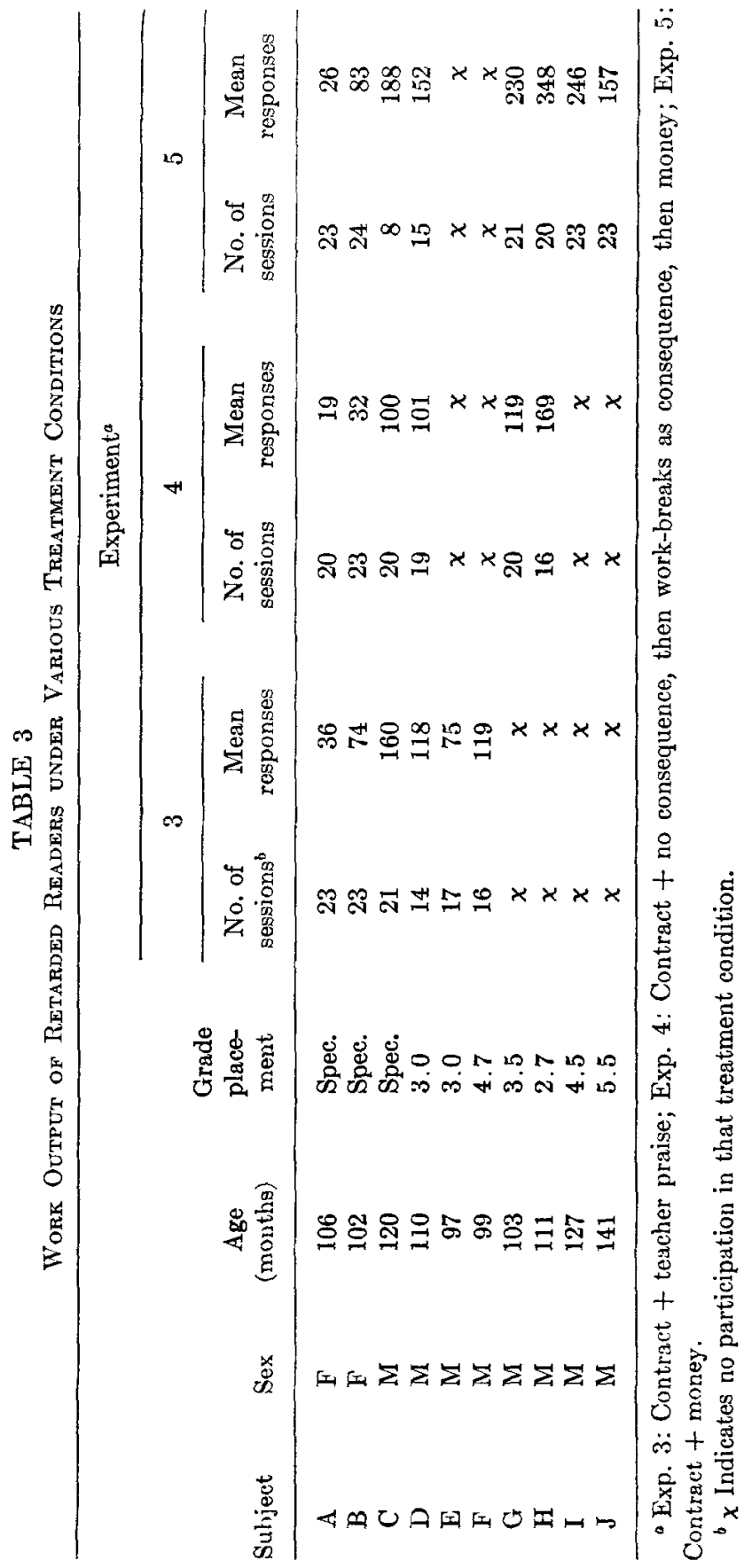




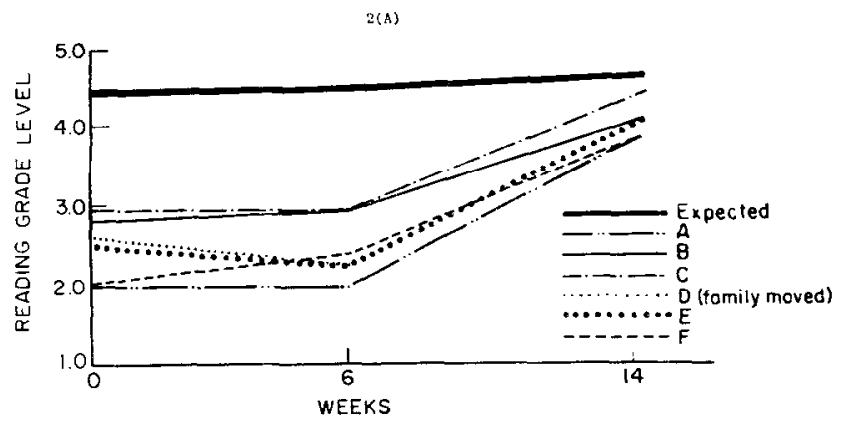

FIr. 2A. Reading achievement of clinic referrals after two periods of treatment with programmed materials in a controlled environment.

Discussion. The condition of a monetary consequence contingent upon task behavior was clearly effective in producing a high rate of work and systematic achievement. There was virtually no rule-testing after ten sessions with this group of relatively disturbed children.

Subjective evidence during the course of the experiment suggested that, while the apparent reinforcer was money, the effective reinforcer might well be feedback information on progress. For example, one child received $\$ .26$ one day and $\$ .05$ the next. He said, wonderingly, "H-m-m. I guess I didn't work very hard today." It was as though he had been previously unaware of his role as a producer.

If feedback is an effective reinforcer, other non-monetary procedures might be as powerful as the money pay-off. A non-monetary procedure might be feasible for public school use. Experiment 6, described later in this report, uses performance feedback rather than money.

\section{Experiment 3: Work Contract with Teacher Praise}

Procedure. Ss were six children referred by their school principals (Table 3, A-F). Three were from special education classes, two read approximately 1 year below grade placement and one read at grade level. The boy who read at grade level was not performing at that level in school and was described as a behavior problem.

Conditions were similar to those described for Experiments 1 and 2. However, children were asked to complete small amounts of work. Agreement to work constituted a "contract." When work contracts were completed, the child brought his work to the teacher who smiled and made comments such as, "Good! You finished. Would you like to do some more?" If the child agreed to do more, the next contract was set. If the child did not agree to do more, he was instructed to go to a non-work area containing play materials. 
Rules were enforcer by asking "What is the rule?" After the children left each day, the amount of work completed by each child was plotted on cumulative curves which were displayed on a bulletin board in the classroom.

Results. Work curves are shown in Figure 3 . Absences are not indicated on the graph, which accounts for the differences in the number of sessions shown for the several children. Ss A and B worked slowly and steadily; Ss D, E, and F slowed down, and S D stopped, then went back to work; $S \mathrm{E}$ had almost completely stopped prior to Session 10.

The acceleration in $S$ E's curve occurred after the student, was allowed to skip exercises if he could read the summaries at the end of exercises. After completing the exercises where that was possible, he stopped working, whereupon he was tested (Session 18) and graduated. He was then

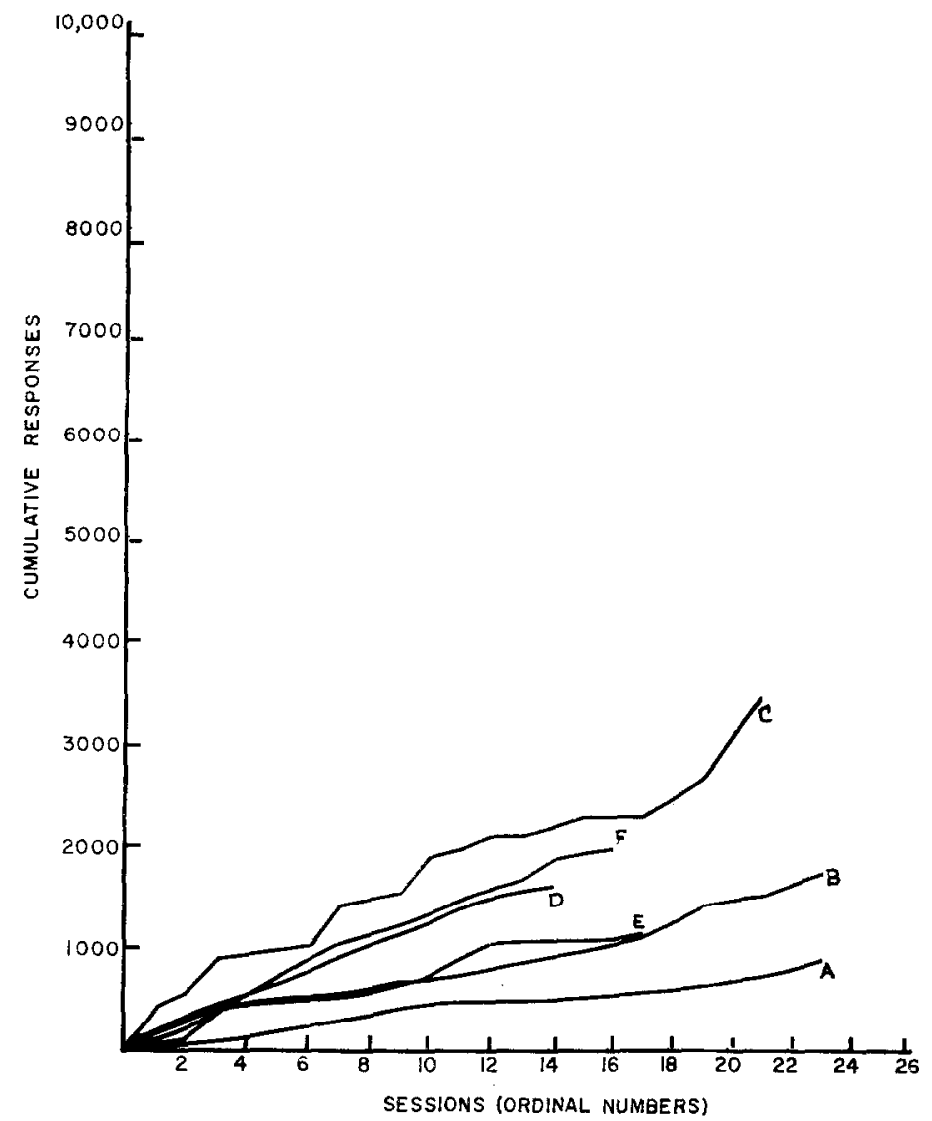

Fig. 3. Wurk output of retarded readers under conditions of work contracts with teacher praise. 
reading above grade level. Until Session 18, curve $\mathrm{C}$ has the general appearance of several small extinction curves superimposed upon a larger extinction curve. The relatively large number of responses in Session 7 occurred as the child stayed beyond the class session to complete a rather large program book. A similar event occurred in Scssion 13. The acceleration following Session 18 occurred when $S$ s D and F were absent often and $\mathrm{E}$ had graduated, reducing the effective class size to three students. Most of $S$ C's work during these sessions was on teacher directed and teacher paced exercises.

Discussion. With one exception, the consequence of teacher praise resulted in rates of work slightly higher than those produced under Experiment 1, No Consequence, but work behavior was not well maintained. Much of the time the children were engaged in activities such as running (quietly) around the room, tapping pencils, etc. Although considerable work was accomplished, working was clearly not the major activity in the classroom. The work curves displayed in the classroom were rarely examined by the children.

Experiment 4: Work Conlract with No Consequence, Work-break Consequence and with Monetary Consequence.

Procedure. Ss were six children; four of them, A, B, C, and D, had taken part in Experiment 3; two of them ( $\mathrm{G}$ and $\mathrm{H}$ ) were new, replacing the child who had graduated and one child who was not re-enrolled for the 6 -week period (Table 3 ). Classes met 1 hour per day, 4 days per week for 6 weeks in the same classroom used in Experiment 3.

No rules were used; the teacher allowed movement, talking, etc., and requested halts or reductions in non-task activity whenever he judged it necessary. Upon completion of a work contract or a work break, the child received the option of another contract or a work-break. Beginning with the 10th session (see (1) in Figure 4), the option was between another contract or a maximum break of 5 minutes; two consecutive breaks were not allowed. Beginning with Session 16 (see (2) in Figure 4), pennies were given to the children upon completion of each contract. The amount per correct response was not specified to the child. He might receive one penny per response upon completion of one contract, one penny per two responses on the next. However, once the ratio of correct responses to pennies was increased, it was not decreased. The maximum ratio was one penny to four responses. Cumulative curves of each child's performance were plotted after class and displayed in the classroom.

Results. Work curves are shown in Figure 4. (The breaks in curves which occur just before procedure changes are due to absences which may have occurred any time the particular procedure was in effect; 
however, curves are aligned at the beginning of each condition in order to facilitale representation of procedure changes.)

There is no general decline in work (and no teacher-paced acceleration). However, prior to the introduction of a "work-break" consequence, there is a deceleration of the four upper curves.

Following the introduction of "work-break" consequences, curves C, D, $\mathrm{G}$, and $\mathrm{H}$ accelerated and then decelerated. Curves $\mathrm{A}$ and $\mathrm{B}$ show no change; the children rarely came in contact with the "work-break" consequences, partly because of low frequency of completing contracts and partly because they occasionally exceeded the time allotted for the break.

Five of the curves show acceleration after the introduction of monetary consequences. The acceleration in curve $\mathrm{C}$ is quite noticeable.

Discussion. Ss A and B did little with the money except to ask what

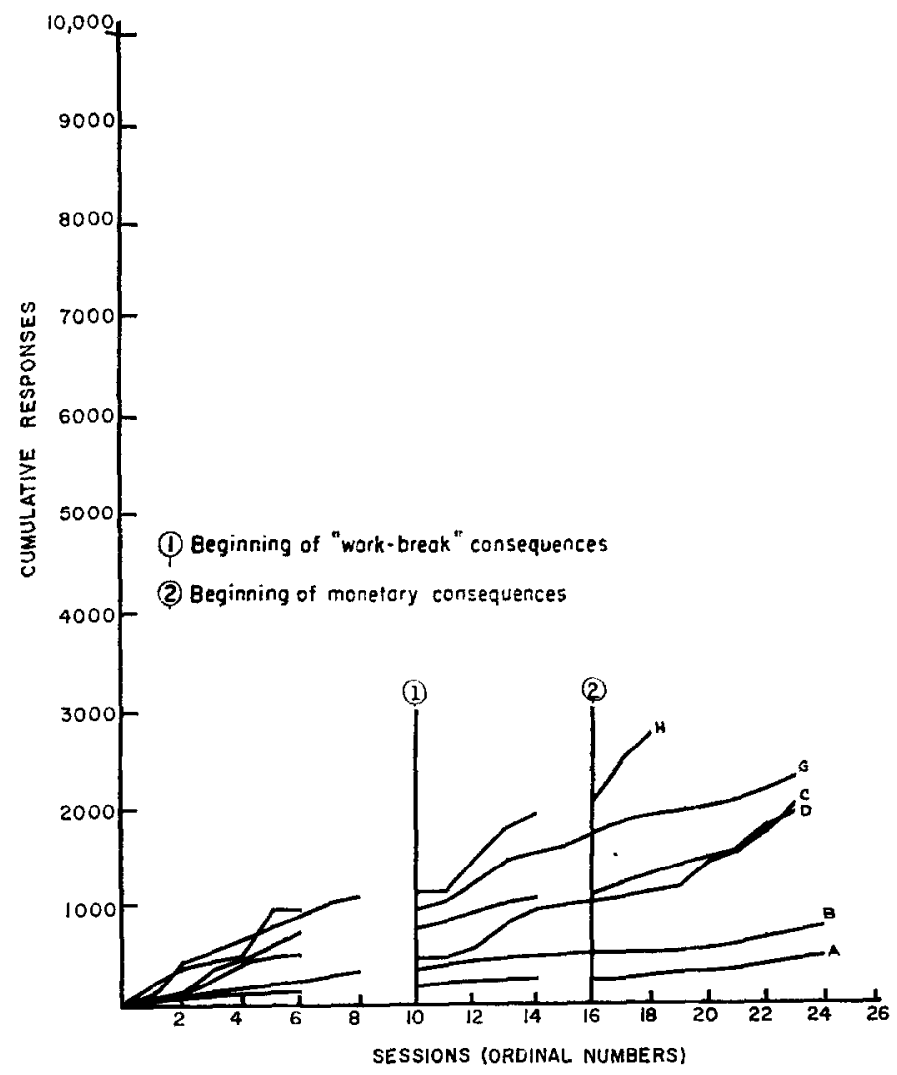

Fig. 4. Work output of retarded readers under conditions of work contract with no consequence, with work-break consequence, and with monetary consequence. 
it was for. After Session 17 the teacher suggested to the parents of the two children that they encourage the children to spend some of the money immediately after class. The subsequent acceleration in the curve for child $B$ may have been due to a resulting increase in the value of the money to the child.

Experiment 5: Work Contract with Monetary Consequence Plus Progress Plotting

Procedure. Procedures were similar to those used in Experiment 4. Ss were eight children A, B, C, D, G, H, I, J, described more fully in Table 3. Child $\mathrm{B}$ was in a different class operated under the conditions described for Experiment 2. Children $I$ and $J$ joined the class after having been a two-person class for a 6 -week period. Child $\mathrm{C}$ was scheduled to attend the class only on Tuesday and Thursday.

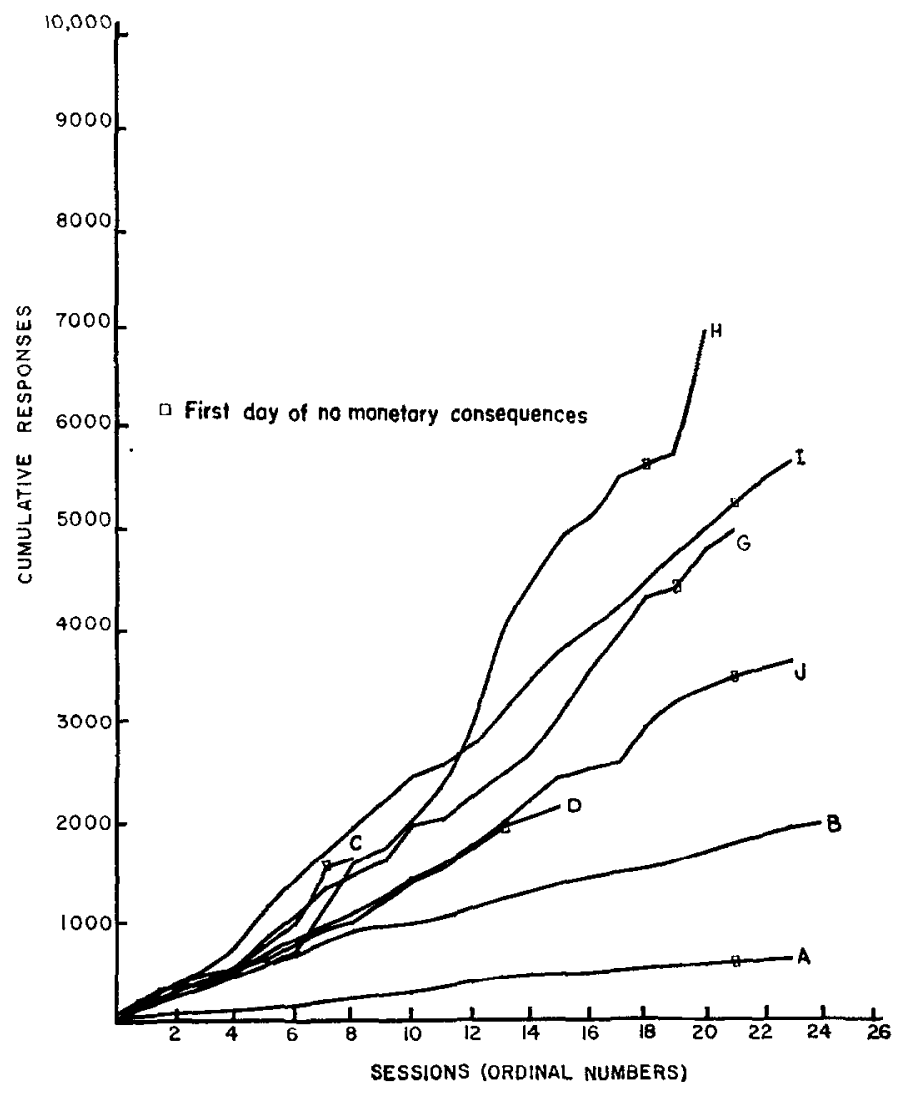

Fia. 5. Work output of retarded readers under conditions of work contract with monetary consequence and work contract with no monetary consequence. 
The class was taught part of the time by a male teacher and part of the time by a female teacher.

The work-to-payment ratio was not stated to the children. Beginning with Session 11, the ratio was systematically increased. In Session 11 it was $5 / 1$, in Sessions $12-15$ it was $10 / 1$, in Sessions $16-19$ it was $15 / 1$, in Session 20 it was $20 / 1$, in Session 21 it was $25 / 1$. There was no monetary consequence during Sessions 22-24. Students graphed their work output at the end of each session throughout the experiment.

Results. The cumulative work curves are shown in Figure 5. Absences are not indicated on the graphs. The performance was maintained throughout the experiment. There is some deceleration in curves $J$ and $\mathrm{H}$ as the ratio of correct responses per penny was increased from $5 / 1$ to $25 / 1$ but the other curves are maintained or even accelerate at the higher ratios.

Curves A, D, I, and $J$ show no noticeable effect on the first day monetary consequences were removed. Ss $H, G$, and $\mathrm{C}$ show an increase on the first day. C, D, I, and $\mathrm{G}$ show a decline on the last day whereas $\mathrm{H}$ shows a large increase and $J$ a small increase.

Discussion. There was little time after the removal of monctary consequence in which to observe effects. The ratio of correct responses/ penny had bcen increased to make the transition to no monetary consequence less dramatic and was apparently successful.

TABLE 4

Age, Reading Achinvement and Work Output under Conditions of Feedrack on Task Behavior

\begin{tabular}{|c|c|c|c|c|c|c|}
\hline \multirow[b]{2}{*}{ Subject } & \multirow[b]{2}{*}{ Sex } & \multirow{2}{*}{$\begin{array}{c}\text { Age } \\
\text { (months) }\end{array}$} & \multirow{2}{*}{$\begin{array}{c}\text { Grade } \\
\text { place- } \\
\text { ment }\end{array}$} & \multirow{2}{*}{$\begin{array}{l}\text { No. of } \\
\text { sessions }\end{array}$} & \multicolumn{2}{|c|}{ Responses } \\
\hline & & & & & Total & $\bar{\chi}$ \\
\hline \multicolumn{7}{|l|}{ I } \\
\hline A & M & 132 & 4.9 & 21 & 5740 & 274 \\
\hline B & M & 98 & 2.9 & 21 & 5725 & 273 \\
\hline C & $\mathrm{M}$ & 124 & 3.9 & 19 & 5150 & 271 \\
\hline $\mathrm{D}$ & $\mathrm{F}$ & 97 & 2.9 & 15 & 2775 & 185 \\
\hline $\mathbf{E}$ & M & 98 & 2.9 & 21 & 3800 & 181 \\
\hline $\mathbf{F}$ & M & 106 & 2.9 & 18 & 2750 & 153 \\
\hline \multicolumn{7}{|l|}{ II } \\
\hline A & M & 151 & 6.9 & 17 & 8175 & 481 \\
\hline $\mathrm{B}$ & $\mathrm{M}$ & 144 & 5.9 & 20 & 9875 & 494 \\
\hline $\mathrm{C}$ & M & 141 & 6.9 & 13 & 4925 & 379 \\
\hline $\mathrm{D}$ & M & 128 & 4.9 & 18 & 5425 & 301 \\
\hline $\mathrm{E}$ & M & 122 & 4.9 & 21 & 4700 & 224 \\
\hline $\mathbf{F}$ & M & 140 & 5.9 & 16 & 2650 & 166 \\
\hline $\mathrm{G}$ & M & 109 & 3.9 & 21 & 3475 & 165 \\
\hline
\end{tabular}


The average response rates shown in Table 3 show a consistent pattern: In all cases where the comparisons can be made, a child's response rate was lower in Experiment 4 than in Experiment 3 and higher again in Experiment 5. Our interpretation of this pattern is that the first 16 sessions of Experiment 4 represent a continuation of the decline in rate observed in Experiment 3. That is, teacher praise and work-break consequences were not sufficient to maintain the responding of the children who took part in both experiments.

\section{Experiment 6: Non-Monetary Consequence, Task Contingent}

As outlined above (Experiment 2: Discussion), if the consequence, feedback of information, is an effective reinforcer in Experiment 2, other, non-monctary kinds of information may maintain task behavior. The simplest of these kinds of feedback appears to be a report of the

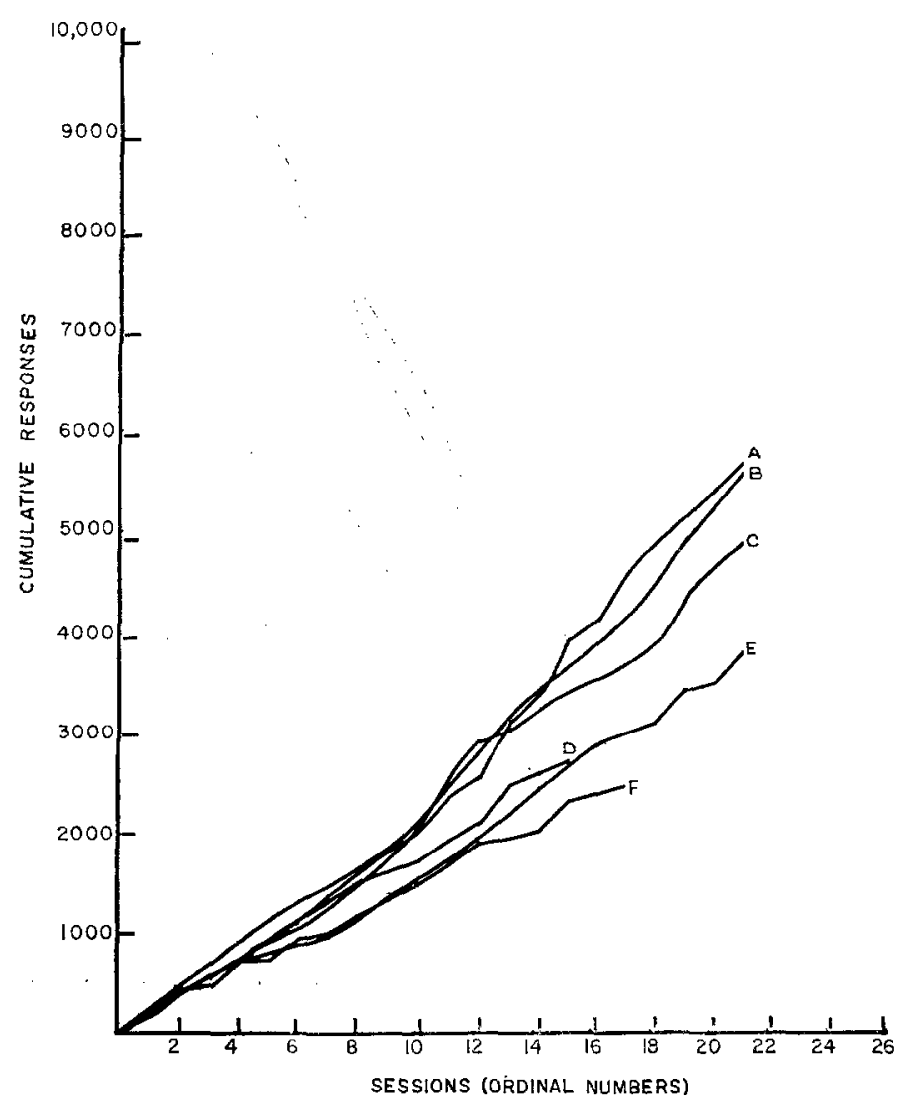

FiG. 6. Work output of retarded readers under conditions of self-selection, selfpacing, and immediate feedback on performance quantity (Class I). 
number of tasks completed, perhaps charted in a way which will allow a daily and weekly comparison of output.

Procedure. Ss were 13 children referred by their principals for treatment. Six were placed in Group 1 with a teacher experienced in operating a controlled environment. Ages ranged from 8-1 to 11-0. Reading deficiencies ranged from .0 grades to 2.3 grades (Table 4 ). One boy, F, was classified as retarded with special room placement. B and $\mathrm{E}$ are twins.

Seven boys were placed in Group II with a teacher recently trained in operating the room. Ages ranged from 9-1 to $12-7$. Reading deficiencies ranged from 1.9 grades to 4.5 grades. Two boys were classified as retarded with special room placement, F (WISC IQ, 82) and G (WISC IQ, 69).

Materials and procedures were those of Experiment 2. The two rulcs

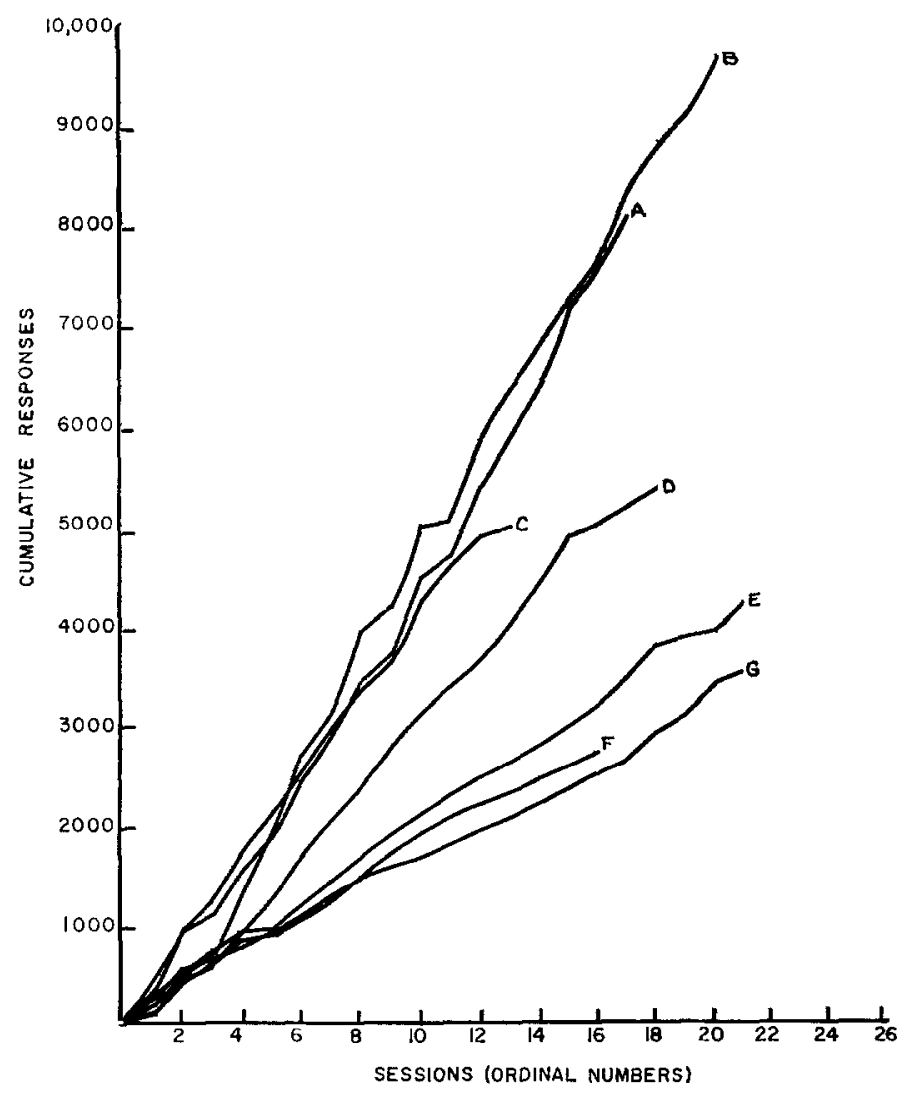

FiG. 7. Work output of retarded readers under conditions of self-selection, selfpacing, and immediate feedback on performance quantity (Class II). 
regarding talking or disturbing others were in effect. At the end of each class, correct responses were counted, in the presence of each child, and he charted his total "points" on a daily bar graph and a weekly cumulative bar graph. No comment was made by the teacher.

Results. Work rates for Groups I and II are depicted in Figures 6 and 7. With the exception of four $S$ s in Group II (Figure 7), the response curves are remarkably similar to those of Experiment 2. The exceptions are $S \mathrm{G}(\mathrm{IQ}, 69)$ whose rate is slower than the others, but similar in configuration, and $\mathrm{Ss} \mathrm{A}, \mathrm{B}$, and $\mathrm{C}$. A and $\mathrm{B}$ appeared to be competing with each othcr. $\mathrm{S} \mathrm{C}$ missed the second week due to a family vacation and worked very rapidly when he returned.

Discussion. Observers reported changes in classroom behavior similar

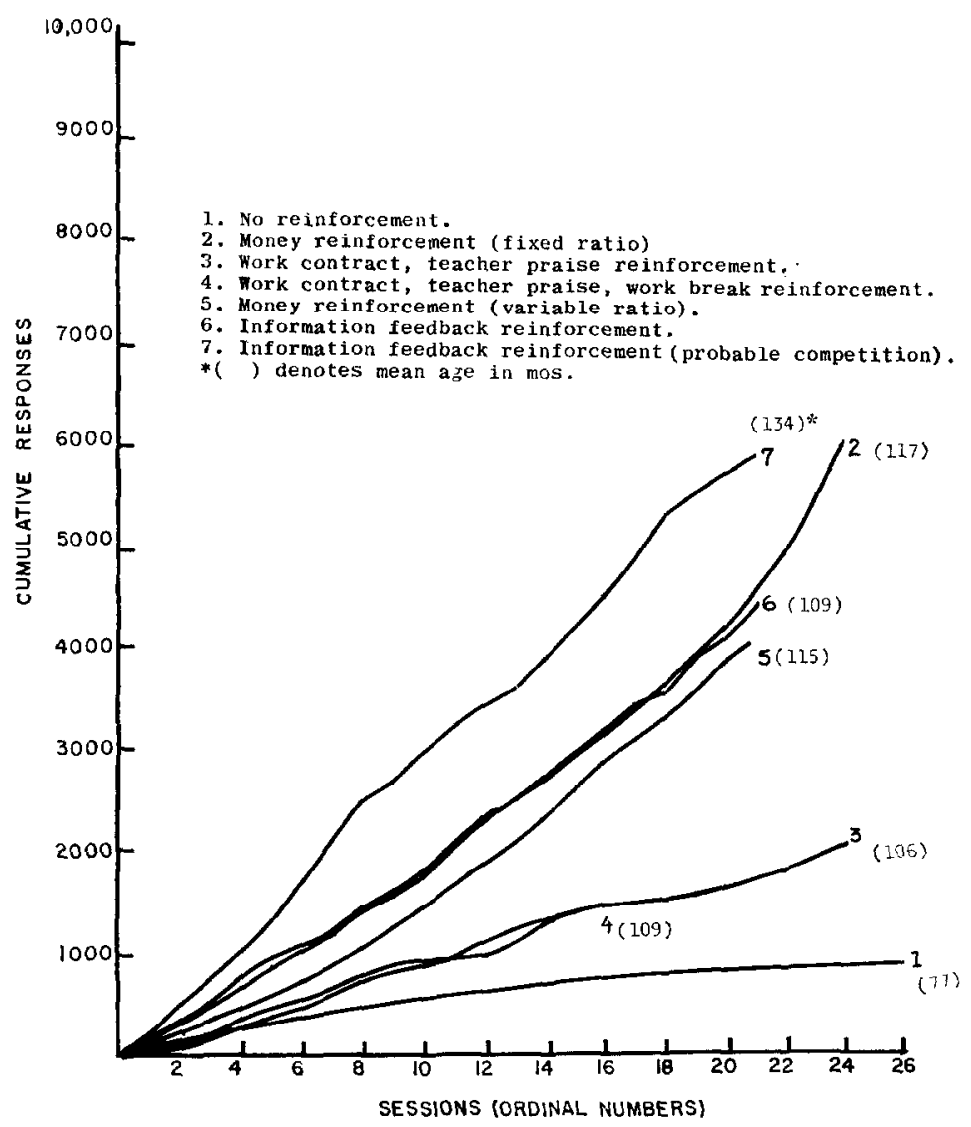

Fig. 8. Median work output of retarded readers under various conditions of reinforcement. 
to those reported in Experiment 2. It would appear, on the basis of similarity of work outputs, that information feedback in the form of "points" is fully as effective as the monetary consequence in maintaining task behavior.

\section{SUMMARY OF RESUITS}

The results of the six experiments are summarized in Figure 8 by plotting the median work output each day for each class. (Classes 6 and 7 were part of Experiment 6.) Experiment 1, no reinforcement, reflects the lowest work output; 3 and 4 (work contract with teacher praise and teacher praise plus work break) are next in order. These conditions are probably most similar to normative classroom conditions in the schools. Experiments 2, 5, and 6 (money or information feedback) appear similar in level of output and in contour. The curve labelled 7 was produced by a group differing in age and grade from the other groups and showing evidence of a three person sub-group who appeared to be competing with one anothor.

\section{DISCUSSION}

There were higher rates of responding in feedback than in non-feedback conditions $\left(x^{2}=10.04, p<.01\right)$.

One possible interpretation of the higher rates is that older children respond at higher rates than do younger children. The groups vary considerably in mean age, from 77 months in Experiment 1 to 134 months in Experiment 6 (Figure 8). In fact, there is a significant relationship between age and response rate: for all Ss taken together, those above the median age of all children tended to respond at rates above the median rate of all children $\left(\chi^{2}=18.9, p<.001\right)$. Similarly, Ss above the median age within a particular class and within a particular treatment condition tended to respond above the median rate for that class and that treatment condition $\left(\chi^{2}=15.4, p<.001\right)$.

Furthermore, students in feedback groups, either money or progress charts, tended to be above the median age $\left(\chi^{2}=10.04, p<.01\right)$, so attributing the results solely to the feedback effect appears to be unwarranted. There is obviously a confounding of age and feedback conditions.

On the other hand, age differences would not seem to account for the differences in the curves in Figure 8. For example, the mean age of $S$ 's contributing to curve 4 is equal to the mean age of $S$ 's contributing to curve 6 . Yet the latter curve is consistently higher and accelerating whereas the former curve is lower and, if anything, decelerating. And 
curve 5 is lower than curve 6 (younger $S$ 's) and lower than curve 2 (older S's).

The problem addressed in these studies is that of maintaining task relevant behavior. Prior clinical work with children in the age range represented here had produced patterns of performance similar to those in Figure 1: deceleration and periods of no task relevant performance.

Examination of all the curves of individual S's reveals that, with performance feedback and/or monetary consequences, performance is maintained or accelerated regardless of age. With teacher praise and/or no performance feedback, performance is not maintained $\left(\chi^{2}=29.7, p<\right.$ $.001)$ regardless of age.

Similarly, examination of the curves of $S$ 's in Figure 3 reveals that a change to a monetary consequence is followed by an increase in task relevant performance $\left(\chi^{2}=5.5, p<.05\right)$. The increase in rate during the several days after the introduction of money is also significant $\left(x^{2}=8.5, p<.01\right)$. Since these curves acceleratc and since those for individual $S$ 's in Figures 5, 6, and 7 are also either maintained or accelerated, we conclude that it is appropriate to attribute the major results to the presence of performance feedback rather than to the age of the S's.

There were monetary consequences throughout Experiment 5 except for the last three sessions. Removal of the money was followed by a range of effects and was not continued long enough to determine whether or not the performance would continue without it. However, the children were already routinely graphing their results before counting their money. As shown by Experiment 6, graphing is a sufficient condition for maintaining task behavior.

\section{SUMMARY}

The work output of retarded readers using a programmed literacy curriculum was observed under various conditions of reinforcement in a controlled classroom. Task behavior was followed by conditions of no consequence, teacher praise, a work-break consequence, a monetary consequence and feedback on amount of work (relative to previous work). Extinction of task behavior tended to occur under conditions of no consequence and of teacher praise. Conditions of monetary consequence and of feedback on progress resultcd in high, sustained rates of work behavior.

\section{CONCLUSION}

The solution to the problem of maintaining task behavior was found to be a simple one. Providing retarded readers with feedback on progress was sufficient to keep them performing at high rates. In effect, they were 
trained to perform desired classroom behavior by an arbitrary, but systematic, point system. The points replaced money within and between experimental groups with no appreciable change in task-relevant behaviors. 